\title{
Autonomy, religious values, and refusal of lifesaving medical treatment
}

\author{
Michael J Wreen Marquette University, Wisconsin, USA
}

\section{Author's abstract}

The principal question of this paper is: Why are religious values special in refusal of lifesaving medical treatment? This question is approached through a critical examination of a common kind of refusal of treatment case, one involving a rational adult. The central value cited in defence of honouring such a patient's refusal is autonomy. Once autonomy is isolated from other justificatory factors, however, possible cases can be imagined which cast doubt on the great valuational weight assigned it by strong anti-paternalists. This weight is sufficient, in their estimation, to justify honouring the patient's refusal. There is thus a tension between the strong anti-paternalist's commitment to the sufficiency of autonomy and our intuitions respecting such cases. Attempts can be made to relieve this tension, such as arguing that patients aren't really rational in the circumstances envisaged, or that other values, such as privacy or bodily integrity, if added to autonomy, are sufficient to justify an anti-paternalistic stance. All such attempts fail, however. But what does not fail is the addition of religious freedom, freedom respecting a patient's religious beliefs and values. Why religious freedom reduces the tension is then explained, and the specialness of religious beliefs and values examined.

Although the literature on refusal of lifesaving medical treatment is vast, there are still, I think, one or two aspects of the issue that need exploring. In this paper I'll be taking a look at one of them. I must admit from the start, however, that my particular topic, and perhaps my treatment of it, are a bit unusual, at least if the typical article in medical ethics is used as a standard for comparison.

\section{I}

Let me begin by reviewing the prevailing view on refusal of lifesaving treatment cases. The view isn't shared by everyone, of course, but it's widely held and plausible, and although typically formulated in terms

\section{Key words}

Refusal of treatment; autonomy; religion; religious values; paternalism; anti-paternalism; bodily integrity; privacy; valid consent. of rights, still applicable, mutatis mutandis, if rightstalk is eschewed.

Consider the case of a normal adult who refuses lifesaving medical treatment. In order to focus on the standard problematic case of this sort, let's assume that the adult in question doesn't have a terminal condition. That is to say, let's imagine that the prescribed treatment would prolong his or her life for an indefinite amount of time, and that the patient's future life, if he or she does undergo treatment, would be relatively free of pain and other untoward conditions. Let's also assume - though in real life the determination of this is fraught with epistemological difficulties - that Walter Weber, the patient in question, is a competent adult, fully cognisant of his condition, his medical options, and the probable consequences of undergoing and not undergoing treatment. Those consequences are, respectively, a high probability for complete recovery and certain death. Finally, assume that Weber's choice to forego treatment is voluntary. To all appearances, then, Weber is a rational, competent, informed adult who is voluntarily choosing not to save his own life in circumstances in which he could save it.

Let me be theoretical about the matter for a moment. If judgements concerning (i) Weber's understanding and appreciation of the (relatively complete) medical information supplied him, or (ii) his rationality, that is, his ability to make decisions based on good reasons, or (iii) the voluntariness of his decision - if any of these judgements were seriously in question, then not honouring his refusal of treatment would be prima facie justifiable. When there's a question as to the validity of the patient's decision, err on the side of his best interests - that's the operative principle of medical practice. The case is altogether different if a minor refuses lifesaving treatment, or if a second party refuses lifesaving treatment for a primary party - then the refusal need not be honoured. But if the conditions for valid consent obtain, then the refusal must be honoured (1). For it is a matter of sheer logic, it might be argued, that if the conditions necessary and sufficient for the validity of a decision that $\mathrm{x}$ be done obtain, then the conditions necessary and sufficient for the validity of a decision that $\mathrm{x}$ not be done also obtain. The validity of a decision cannot be even partly a function of what is decided. What the conditions 
necessary and sufficient for the validity of a decision ensure is precisely that whatever is decided is validly decided. So it could be argued, and very plausibly.

For the case at hand, what this means is that Weber's decision not to be administered lifesaving medical treatment must be honoured. By hypothesis, all of the conditions for valid consent have been satisfied, yet Weber has chosen not to undergo treatment.

Insisting on the satisfaction of the conditions for valid consent, but also insisting that if they're met the decision should be honoured, is insisting that patient autonomy is of fundamental ethical importance. In fact, in the circumstances envisaged it's to insist that autonomy is a more important value than patient utility. That, the case at hand tells us, is true even when the disvalue in question is death itself. Problematic refusal of treatment cases thus show us how strongly anti-paternalistic we are.

\section{II}

Such is the standard position on a certain kind of problematic refusal of lifesaving treatment case. But although I'm basically a proponent of the position myself, I think it needs a little probing (2).

Consider the main theoretical argument used to support it, the argument of four paragraphs back. It sounds cogent, but several doubts may creep in. One is that if autonomy really is all that important, if autonomy automatically overrides considerations of large patient utility, why doesn't it do so when considerations concerning someone else's utility, even someone else's large utility, are at stake? If autonomy is what matters, why should whose utility it is matter? I have an answer to the question - though this is not the place to rehearse it - but here all I want to point out is that it deserves an answer.

But secondly and, in a sense, more disturbingly, what I called the operative principle in refusal of treatment cases, namely that when there's a question as to the validity of the patient's decision, we ought to err on the side of his best interests, just doesn't seem to apply outside of the medical context. If health-related values aren't at stake, then if a person doesn't pose a (physical) threat to himself or (a physical or psychological threat) to others, he is (at least in the United States) allowed to do as he pleases, even if he's of questionable mental competence, and even if it's questionable whether he understands and appreciates relevant information supplied to him. This is true even if what he chooses to do is clearly not in his best interest. Why should such a principle be valid within the medical context but not outside it? (Or, more accurately, why should it be valid, but its mutatis mutandis cousins not be?)

But last and, I guess, most nebulous of all is the question that I'll be exploring at some length here: Why should autonomy, just as such, have that sort of moral weight? I'm not challenging the fact that autonomy is very important, just questioning why it should be accorded that much weight, enough to

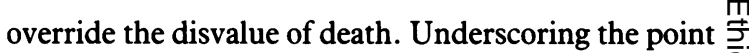
is that the abridgement of autonomy in the case of the unwilling Weber is relatively slight. Only a forced $\Rightarrow$ transfusion, say, or only the administration of $\stackrel{?}{?}$ medication is at issue. This does make me question my strong, native anti-paternalism, and thus question the standard position.

\section{III}

To drive the point home, let me build one more detail into the case of the woeful Weber. Suppose that Weber satisfies all of the conditions mentioned above, but that when asked why he was refusing treatment, he said something like: 'I just feel like it; no particular reason other than that,' or: 'Out of whimsy. I decided to let the flip of a coin decide my fate' (3). Here it's a question of pure autonomy: in the circumstances envisaged, no values other than patient autonomy - not even prudential values that the patient assumes will be $ᄋ$ secured for him by refusing treatment (4) - are weighed against the disvalue of death (5). When the issue $\infty$ concerning autonomy is clarified this way, $I$, for one, $\frac{\mathbb{D}}{D}$ start to feel even more uncomfortable with my strong anti-paternalism. I begin to think that maybe I $\frac{}{8}$ shouldn't assign autonomy quite so much weight; I $\triangle$ begin to think, in other words, that if that's all that $\overrightarrow{0}$ Weber has to say in defence of his decision, then may he ought to be transfused (assuming, for simplicitys. sake, that a transfusion is all that's needed to save his life), despite the fact that a transfusion would be an abridgement of his freedom and a violation of his autonomy. That, at least, would be my growing intuition on that matter. Moreover, it's an intuition that can be fertilised if we add that Weber wouldn't be particularly angry about our transfusing him, and that he wouldn't attempt suicide later.

\section{IV}

One way to hold fast to a strong form of antipaternalism while believing that it would be permissible to transfuse Weber in the circumstances envisaged is to deny that the conditions for valid consent, and thus for valid refusal, obtain. Anyone who would make a decision that has such major prudential consequences on the basis of whimsy and who, moreover, would stick with that decision despite its severe untoward consequences for himself, thereby $\sigma$ demonstrates his irrationality. And if he's not rational, N the argument would conclude, his decision isn't valid, N and so needn't be honoured. Once again, the argument is quite plausible.

But not quite plausible enough to convince me. Granted, anyone who would make Weber's decision on of his grounds is prima facie irrational; still, in the case at hand Weber's rationality can't be seriously questioned. By hypothesis, he has a set of values, can reason in accordance with them, understands and fully $\frac{?}{\mathbb{D}}$ appreciates the medical information given him, and is $\varrho$ acting in a voluntary manner. If we need to we can add that his prior decisions, all of them, are quite rational 
by anyone's standards. Thus if we put to the side for just one moment a single fact about Weber - that he has refused treatment for trivial or whimsical reasons everything we know about him points unequivocally to one conclusion: he's a rational agent. His rationality, independent of the case at hand, is assured. Although the case at hand is evidence - strong evidence - that, overall, Weber isn't rational, it probably isn't strong enough to overturn the positive judgement that, overall, he is.

Besides, even if it were, it's questionable whether it would be admissible evidence. Judgements of a patient's competence to make a decision are judgements that have to be based on grounds wholly independent of what the patient's decision is and what his reasons for that decision are. Without wholly independent grounds for a judgement of rationality or competence, 'honouring patient autonomy' and 'honouring patient decisions' are just empty phrases; for otherwise, if the patient's decision isn't what others think it should be, based on their reasons and values, a judgement of incompetence could be issued, and the patient's decision overridden. That's equivalent to saying that the patient is free to decide, and his decision will be honoured - but only as long as he decides a certain way. The cash value of such freedom and autonomy is zero.

Let me sum up this discussion. Although the case of the whimsical Weber is peculiar, and although, given the nature and grounds of his decision, we're strongly tempted to say that, overall, he's not rational, and thus that his decision isn't valid, the last of these conclusions, at the least, should be resisted. The evident tension between our budding paternalistic intuition in the case of Weber and the strong antipaternalistic sentiment that we harbour in general, thus remains (6).

\section{V}

Perhaps that's why values other than autonomy are frequently cited in legal cases involving refusal of lifesaving treatment. The most prominent of such values are privacy, bodily integrity, and religious freedom; in addition to autonomy pure and simple, all three have been invoked as grounds for honouring refusal of treatment requests. But would any - or all of them help to ease our cognitive tension?

At least the first of them wouldn't. Although privacy is frequently cited in the legal and philosophical literature on abortion, the concept is clearly irrelevant both in the case of abortion and in the case of refusal of treatment. Assault isn't an invasion of privacy, and neither is battery, yet both would have to be counted as such if privacy were the operative value in abortion or refusal of treatment cases. What both assault and battery involve is not an invasion of someone's privacy, but an invasion of his bodily integrity. Bodily integrity has to do with having one's body treated as an integral unit. The value of bodily integrity is presumably what the right not to be touched (in a broad sense of the term) against one's will, the right not to suffer bodily injury at the hands of another, and perhaps the right to have an abortion, are based on (7). Privacy, which has to do with the control and disclosure of information about and to oneself, doesn't have anything to do with it. And, for exactly the same reason, neither does it have anything to do with honouring refusal of treatment requests. The grounds, once again, really have much more to do with bodily integrity: the patient is touched against his will.

But is bodily integrity enough to add to autonomy pure and simple to arrive - unquestionably arrive - at the standard position on cases like that of $\mathrm{Mr}$ Weber? Maybe. But maybe not. After all, bodily integrity is already present in the full-blown case of section III, and our beliefs about honouring the whimsical Weber's refusal of treatment at that point were very much in a state of tension. Even if the answer is yes, then, it's not a clear yes.

\section{VI}

Apparently what's needed to get an unequivocal yes answer is the addition of a value that's not necessarily present in all refusal of treatment cases (as bodily integrity necessarily is, and as autonomy by hypothesis is). This is where the third major ground frequently cited in the literature, religious freedom, comes in. The value of religious freedom is basically the value of pursuing religious values freely decided upon and acting in accordance with them. As such, it's an extrinsic value, one not necessarily found in all refusal of treatment cases. Add the value of religious freedom, then, and the issue seems clearly decided in favour of the standard position: Weber shouldn't be transfused against his will.

Now that much does seem clear. The case of a competent adult Jehovah's Witness who refuses lifesaving treatment tells us as much, independently of our investigation of the wilful Weber. In such cases, it clearly seems correct to say that the Witness's refusal of treatment should be honoured.

But I still have a question or two.

\section{VII}

The first, a preliminary one, is whether the notion of religious freedom makes sense at all. 'Despite its widespread use', someone may ask, 'isn't the concept really self-contradictory, or at least self-undermining?' The argument for this view is that religion is actually antithetical to autonomy because it psychologically limits the number of possible courses of action that the believer considers and, more importantly, makes him unable even to entertain courses of action proscribed by his convictions. Religion thus effectively reduces the believer to the pre-adult level and, as long as he continues to believe, forces him to remain on that level. The result is not autonomy but heteronomy (8).

While a complete response to this objection isn't possible here - that would entail an extended discussion of both autonomy and religious belief - and 
while the argument must be admitted to have some force in some circumstances - think of some of the Moonies - as it stands it is far too sweeping. There is a difference between simply believing something and acting in accordance with one's belief, and being brainwashed, and brainwashed in such a way that responsibility for one's actions is effectively removed. The former is all that is entailed by religious belief, but the former is compatible with free choice, and even required by it. The latter isn't compatible, but it's a caricature of the great majority of the world's religions. Religion as such, then, is no more corrosive to autonomy than any other comprehensive system of beliefs and values, secular humanism, presumedly a citadel for free choice, included.

But the most important question to ask is why religious freedom - pursuing religious beliefs and values freely decided upon - is looked upon altogether differently from other sorts of beliefs and values. It's regarded as justifying, or at least as adding significant weight in justifying, a decision to honour a patient's refusal of treatment. Other beliefs and values a person might have aren't weighted nearly so heavily. If I believed the world would be a better place if the number of red objects in it were maximised - if that belief encapsulated one of my fundamental values and if I refused treatment on the basis of it - believing, for example, that the blood drained from my body would fill several bottles - my fundamental value would be of little justificatory moment. It would simply be on a par with Weber's whimsy. It wouldn't dissipate the intuition that it would be ok to administer a transfusion, in other words, even though religious values seem to be able to do just that, or at least to help in a significant way to do just that. Why is there this important difference between the two?

Four possible answers suggest themselves. The first is that religious values are more important to a person than red-object values. The second is that the United States constitution guarantees freedom of choice based on religious beliefs and values, but issues no such guarantee in regard to red-object beliefs and values. The third is that no one knows whether any religious beliefs are true, much less which ones are, and so no one can judge their admissibility. Not so in the case of red-object beliefs and the values predicated upon them. Such beliefs are clearly wrong, and their concomitant values wrong-headed. Fourth and last, religious beliefs and values fit, or can fit, into a rational person's life in a way that red-object beliefs and values cannot, and the way that they fit - which will be explained below - should make an important difference in the way we regard, and so treat, the person who has them.

Of these proposed explanations of the specialness of religious beliefs and values, the first two can be ruled out very quickly. Red-object beliefs and values might be thought to be as important by one person as religious beliefs and values are by another. As for the United States constitution: the question is not the legality of honouring refusals of treatment, but the morality of doing so. The constitution supplies us with no guidance on that count. Moreover, even if we knew that the constitution was an infallible moral authority, the philosophical question would remain. That question is: Why differentiate between the two sorts of beliefs and values? On the hypothesis in question that's equivalent to: What are the reasons that the infallible authority has for differentiating between the two? If we knew the answer to that question, we wouldn't have to make reference to the infallible moral authority at all.

Nor is the third answer in much better shape. If we were ignorant in respect to some other matter - say, the chemical composition of the atmosphere of Pluto - and Weber had strong beliefs and values respecting it, we wouldn't recognise our ignorance as providing any justification for honouring Weber's request. Such ignorance would provide no justification at all. If ignorance calls for anything, what it calls for is for us to get rid of it, that is, to find out the truth on the matter. But even if we do find out the truth, knowledge wouldn't necessarily provide justifying grounds. It wouldn't in the case of the atmosphere of Pluto, for example, no matter what the truth about its chemical composition may be. The truth on such matters is simply irrelevant to the issue.

But the truth on matters such as religious beliefo might well be a relevant factor; the truth or falsity of religious beliefs does seem to make an importan valuational difference. Take the case of a Jehovah's Witness. A Witness believes that if he receives a blood transfusion, he'll be denied entrance into heaven. If that belief is true, important prudential consequences follow. The same is true for many, many religious beliefs. What we should really do, then, is find out which, if any, of them are true.

Ignorance about them, however - neither knowing nor not knowing whether they're true - would seem to call for a conservative judgement no matter what the particular religious beliefs of a patient may be: what we ought to do, given what we know, is whatever is in the patient's best interest. In the case at hand, then, ignorance would, if anything, reinforce the judgement that it would be permissible to override Weber's autonomy for the sake of considerable personal utility.

Finally, we can ask what difference it would make if we knew that the patient's religious beliefs were false. Would that help to justify a paternalistic decision in the case of, say, a Jehovah's Witness? It wouldn't if we were stalwart anti-paternalists, of course; but then again, stalwart anti-paternalists would never have arrived at this juncture in the first place, for they never would have been swayed in the least by considerations of massive personal utility at the beginning of our investigation. Still, I think that the anti-paternalist position on the matter has to be the right one. It's not the truth or falsity of the religious beliefs that the person holds that's relevant so much as that they're his beliefs and - the point that I want to emphasise - that they're the kind of beliefs they are. 


\section{VIII}

This brings me to my fourth proposed explanation of the specialness of religious beliefs and values, and the one I think correct. Religious beliefs and values can fit into a rational person's life in away that red-object beliefs and values, and Pluto-atmosphere beliefs and values, cannot. The way they do should make for an important difference in the way we regard, and so treat, the person who has them.

In the Western world, religious beliefs and values typically have a lot to do with such matters as: the existence of a Supreme Being who created and sustains the world; our relation to this Being; the fundamental nature of the Earthly realm; our place in this realm; what He has planned for us; what He demands of us; the survival of our bodily death; the nature of continued existence after bodily death; our relations, moral and otherwise, with our fellow human beings; and our relations with other animate beings and the environment.

As can be seen, religious beliefs and values typically make reference to the most basic limitations on human life. They thus implicitly or explicitly recognise and take seriously a number of pervasive and important facts. Such facts include: that no matter what steps we might take to put off the event or hide the fact from ourselves, we all eventually die; that external conditions about which we can do nothing circumscribe our existence, and must be attended to if we are to continue to exist (I have in mind the empirical conditions needed for the development and maintenance of human beings); that the historical circumstances we are born into and live within aren't of our own choosing, and neither are our character traits, personality traits, proclivities, or cognitive tendencies; that our choices, and even the situations in which we choose, similarly seem to be due to factors beyond our control; that our actions may have effects beyond our control, or even beyond our wildest imaginings, and that such effects may be altogether different in character from those we intended; that we are all 'noble in reason, infinite in faculty', yet are doomed to actualise only a tiny fraction of our potentialities and fulfill an even tinier fraction of our aspirations; that we can, indeed must, live with others; that the natural world we find around us isn't made in our image, and is indifferent to us, and even hostile at times.

In an important sense, then, religion has to do with (i) describing and explaining the human condition at its most fundamental level; (ii) providing a person with a unique concept of personal identity, in the fullest sense of the term; and (iii) making sense of ourselves and the world around us in a complete and satisfying way. One of the primary pieces of the business of religion, in short, is to give a sense to the expression 'the meaning of life'. It reconciles us, at a deep existential level, to ourselves, to our world, to each other, and, most of all, to our limitations and relative impotence. Religious beliefs and values are therefore not on a par with other beliefs and values a rational person might have, such as ones regarding red objects, however dear to a person's heart such beliefs and values may be. By their very nature religious beliefs and values circumscibe and interfuse other beliefs and values, and permeate all of them to some extent. That's why they're not of the same order, cognitively or valuationally, as other beliefs and values.

The reason why religious beliefs and values are special, then - the reason why they may provide the extra justificatory push that's needed, if any is, to say that we definitely ought to respect a Jehovah's Witness's refusal of treatment, even if it's questionable whether we ought to respect Walter Weber's - has to do with this pervasive, supremely important integrating and reconciling function that they have in a person's life. In an important sense, they fill out the person, and are integral to his personal identity and sense of himself. Not to respect an autonomous person's refusal of treatment when that refusal is religiously based is not to respect him as a person at the deepest level, the level at which he has tried to reconcile himself to the limitations of his own human existence, and the level at which he has made the attempt (even if very misguidedly) to find out who he is, what his place in the world is, and what the nature of this sorry scheme of things entire is. Indeed, if a nonreligious ideology can do all of these things, can perform the pervasive, special integrating and reconciling function just mentioned to the extent and at the level that a religion can, then I think the same holds for it (9). Not honouring a person's refusal would be a personal insult of a very deep and cutting nature. That, I think, is why religion is special, and why it's so often cited as an 'external' justificatory consideration in refusal of treatment cases.

\section{IX}

Let me summarise my findings, and argue for an additional point or two.

The standard position on a certain kind of refusal of lifesaving treatment case is that patient autonomy is sufficient to justify honouring a patient's refusal. This position has a great deal of intuitive appeal, but at least three major problems attend it. The third of them, and the only one pursued at length here, concerns the enormous moral weight that it accords autonomy. Autonomy is accorded so much moral weight that its exercise can outweigh a tremendous amount of personal disutility. For anyone not already fully convinced that paternalism couldn't possibly be justified, the intuitive appeal of the standard position may fade somewhat when this is realised and its implications noted. For when autonomy is isolated from other values, an autonomous patient might refuse treatment for utterly trivial, laughably whimsical, or grossly irrelevant, reasons. A paternalistic response then gains markedly in intuitive appeal, and may even present itself as a viable moral alternative.

If this is right, there is a tension between the 
intuition that autonomy is rightly accorded very substantial moral weight and the intuition that it would be permissible to administer lifesaving treatment against an autonomous patient's will. Let me be clear about this tension. For the dogmatic anti-paternalist there is no tension and no problem (10), because the paternalistic intuition such cases elicit is simply given no credence. For the strong anti-paternalist who isn't dogmatic, however, there is a tension to be resolved even if anti-paternalism is ultimately opted for, simply on the ground of autonomy. There is a tension for him because he doesn't automatically discount the appeal of the paternalistic intuition, but feels he must come to grips with it. On the other hand, for the less antipaternalistically inclined, the tension is palpable. Pressure sufficient to downgrade autonomy's moral import is being exerted in such cases. The tension is there, then, even if, as with the fairly strong antipaternalist, you think that the patient's refusal ought to be honoured even though his reasons for refusal are trivial, whimsical, or irrelevant. However, for all but the dogmatic anti-paternalist, the tension has to be recognised, and some attempt made to resolve it.

But several attempts to do so fail. It won't do any good to argue that the person who refuses treatment on trivial, whimsical, or irrelevant grounds isn't rational, and so autonomy retains its massive weight while paternalism is justified. That argument is defective on several counts. And it won't do any good to argue that privacy or bodily integrity add enough to autonomy to tip the scales in favour of anti-paternalism, and thus ease the tension. The first is an irrelevant value in the circumstances envisaged, and the second is already present in the cases of refusal of treatment that generated the tension in the first place.

Extrinsic values, ones not present in all refusal of treatment cases, are apparently what are needed to ease the tension. But not all of them will do - whimsical ones, for example, won't because they're responsible for the problem in the first place. Religious values, however, are frequently cited in this regard, and they are able to do the trick; that is, they are able to justify anti-paternalism. If our intuitions didn't tell us as much, the case of Jehovah's Witnesses would. But why are religious values so special? Why are they, if present with autonomy, unequivocally able to justify antipaternalism?

Four answers might be tried, but only one of them, an answer which, in brief, has to do with religion's place in securing a sense of personal identity and providing life with a meaning, is able to secure the specialness of religion.

But where does this leave matters for the relatively strong anti-paternalist like myself, and where does it leave them for the not-so-strong anti-paternalist? The question has to be asked because religious beliefs and values are extrinsic, not necessarily present in all refusal of treatment cases. Well, it leaves the not-so-strong anti-paternalist with a justification for anti-paternalism only if there are some extrinsic beliefs and values - preferably religious ones - present. If there aren't, considerations of personal utility outweigh wanton autonomy. Even if that position is wrong, it's certainly not silly. For the strong but not dogmatic antipaternalist, the presence of religious beliefs and values eases tensions and makes him more secure in his antipaternalistic stance. But if such beliefs and values, or comparable ones, aren't present, he would still honour the patient's refusal of treatment. Bare autonomy has that much weight, he thinks, and that probably for a reason connected with the reason that makes him feel more secure if religious beliefs and values are present: autonomy records the fact that a person, a self-directed and responsible being, is being dealt with, and not a mere receptacle for utility and disutility.

But no matter which of the two positions you find more attractive, one thing I hope to have shown is why both can draw solace from the presence of religious beliefs and values. That, I think, shows why religious beliefs and values are important, indeed special, in such cases.

Michael Wreen is Associate Professor of Philosophy at Marquette University, Milwaukee, Wisconsin 53233, USA.

\section{References}

(1) Other things being equal. Countervailing considerations concerning the secondary effects that a patient's refusal might have on others - burdening the state with the support of small children, for example, or creating a public health hazard because the patient has a dangerous and highly communicable disease - might override the prima facie case for honouring a patient's refusal of treatment.

(2) A good recent article that rejects the standard position outright is Eastman N L G and Hope R A, The ethics of enforced medical treatment: the balance model, fournal of applied philosophy 1988; 5: 49-59. Eastman and Hope propose a model for dealing with refusal of treatment cases that doesn't assume that the refusal of an autonomous patient should automatically be honoured. Rather, on their view, autonomy is a degree concept and autonomy must be weighed against personal utility. Thus for them, autonomy and utility aren't serially ordered (meaning the first has to be satisfied before the second is even considered), as they are on the standard position. Their position, although it accords autonomy a fair amount of weight, is one form of (what I call below) not-so-strong anti-paternalism.

(3) The coin came up tails.

(4) I have in mind such values as the enjoyment of eternal bliss that a Jehovah's Witness assumes will be secured him - or at least not lost him - if he refuses a needed blood transfusion.

(5) But see below, section V. Actually other values are present. We can ignore them for the nonce, however.

(6) One might also attempt to resolve it by distinguishing between competence tout court and limited or intermittent competence. (For this distinction, see Beauchamp T and Childress J, Principles of biomedical ethics Oxford: Oxford University Press, 1979: 67-68.) 
Weber is competent tout court, it could be argued, but not competent to make medical decisions. On those grounds, then, his decision to forego treatment could be argued to be not valid, and thus the tension mentioned in the text could be resolved. But clearly this is merely an ad hoc manoeuvre and, moreover, one that's heir to the objections mentioned above.

(7) I say that bodily integrity is perhaps a (partial) ground for a right to have an abortion, because it's questionable whether pregnancy can be viewed as an interruption or a disruption of bodily integrity at all.

(8) My thanks to an anonymous referee for bringing this objection to my attention.
(9) My thanks to a second anonymous referee for bringing this point to my attention. I do think, though, that any ideology that can do all of this is probably best viewed as a religion. Certainly, many ideologies fail the test. Marxism, for example, fails because it doesn't provide its adherents with a unique concept of personal identity. There is still a difference, I want to say, between a philosophy, even a comprehensive, systematic philosophy (which I'm not sure Marxism is), and a religion.

(10) The real-life Walter Weber, the author's best friend, is a dogmatic anti-paternalist, I've just discovered! Wouldn't you know it! 